\title{
Effect of AC-264, a Novel Indole Derivative, on Apoptosis in HL-60 Cells
}

\author{
Kyeong Lee, ${ }^{a}$ Ok-Kyoung Kwon, ${ }^{\dagger,}$, Yan Xia, and Kyung-Seop Ahn ${ }^{\dagger, *}$ \\ College of Pharmacy, Dongguk University-Seoul, 26 Pildong-3ga, Jung-gu, Seoul 110-715, Korea \\ ${ }^{\dagger}$ Immune Modulator Research Center, Korea Research Institute of Bioscience and Biotechnology, 685-1 Yangchung-ri, \\ Ochang-uep, Cheongwon-gun, Chung-buk363-883, Korea. E-mail: ksahn@kribb.re.kr \\ Received September 27, 2010, Accepted November 2, 2010
}

\begin{abstract}
The anticancer effect and apoptotic mechanism of a novel indole derivative AC-264, a lead derived from a chemical library, were investigated in human promyelocytic leukemia HL-60 cells. HL-60 cells treated with AC-264 at various concentrations showed the morphological features of apoptosis, such as plasma membrane blebbing and cell shrinkage. AC-264 exhibited cytotoxic effect in various cancer cell lines with different degrees of potency. Especially, AC-264 was effective on increasing the population of apoptotic cells in HL-60 cells, as detected by the number of cells stained with Annexin V and PI. Furthermore, AC-264 activated caspase-3 enzyme activity and induced internucleosomal DNA fragmentation. These results indicated that AC-264 produces anti-cancer effect via apoptotic cell death by activating caspase- 3 and inducing internucleosomal DNA fragmentation in HL-60 cells.
\end{abstract}

Key Words: Indole derivative, Apoptosis, Caspase-3, DNA fragmentation

\section{Introduction}

Apoptosis is essential for normal development and the maintenance of homeostasis. It is involved in a variety of clinical disorders such as cancer, autoimmunity, hematopoietic disorders, and infertility. Many current anticancer drugs kill particular types of tumor cells through apoptosis. Apoptotic cells are characterized by specific morphological and biochemical changes, including cell shrinkage, chromatin condensation, budding, and internucleosomal cleavage of genomic DNA. The process is tightly regulated and mainly orchestrated by a family of cysteine proteases called caspases. ${ }^{1-3}$ Two main apoptosis pathways have been identified, the death-receptor pathway and the mitochondrial pathway. The death-receptor pathway is triggered through ligand binding to receptors in the plasma membrane, such as the Fas/CD95 and TNFR1, which subsequently activate caspase- 8 and downstream caspases. The mitochondrial pathway involves the activation of caspase- 9 which in turn activates downstream executioners. ${ }^{4-6}$ However, both of the two pathways converge at the level of caspase- 3 activation, resulting in chromosomal DNA fragmentation. ${ }^{7}$ Apoptosome-activated caspase- 3 can then trigger hallmarks of apoptosis by proteolytical cleavage and activation of a DNase, which mediates DNA fragmentation. ${ }^{8-10}$ Caspases are not the unique mediators of programmed cell death. Serine proteases are implicated in cell death occurring without activation of caspase family members, or sequentially related to caspases. ${ }^{11-13}$

In recent years the regulation of cell cycle and apoptosis has received much attention as a possible means of eliminating excessively proliferating cancer cells. Cancer occurrence requires the failure of the apoptotic safeguard mechanisms as well as the deregulation of the cell cycle. ${ }^{14}$ Virtually many anticancer approaches including chemotherapy, hormones and radiation, induce cytotoxicity of tumor cells by apoptosis. ${ }^{15-16}$ Initiation of apoptosis is controlled by regulation of the balance

${ }^{\mathrm{a}}$ These authors equally contributed to this work.

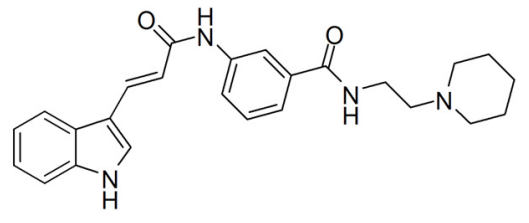

Figure 1. Structure of a novel indole derivative AC-264.

between life and death signals received by the cells. ${ }^{17}$ It has been reported that the anti-tumor efficacy of several chemotherapeutic agents are correlated with their apoptosis-inducing ability. ${ }^{18}$ Therefore, the identification of apoptosis inducers represents an attractive approach for discovery and development of potential anticancer agent.

Of note, a variety of indole-containing compounds have been reported to exhibit anti-apoptotic properties, including 3-aroylindole compound BPR0L075, indole-3-acetic acid (IAA), and 3-Amino-1,4-dimethyl-5H-pyrido[4,3-b]indole (Trp-P-1). ${ }^{19-21}$

As part of our ongoing research program for anticancer chemotherapy, we have constructed synthetic chemical library via derivatization of commercially available trans-3-indoleacrylic acid was screened using MTT assay. An indole derivative AC264 (Fig. 1) was chosen as a lead compound because of its novel structure and potency, and further evaluated for its anti-cancer effect. Herein, we examined the effects of AC-264 in human promyelocytic leukemia HL-6 cells and other cancer cell lines. Particularly, we observed the preference of AC-264 to induce apoptosis of HL-6 cells, and the possible mechanisms involved in the apoptotic effect of this compound were investigated.

\section{Experimental Section}

Chemistry. The chemical library was constructed via derivatization of commercially available trans-3-indoleacrylic acid. The screening results of our chemical library, synthesis and 
characterization of AC-264 were described in the supporting information. Stock solutions were prepared by using DMSO as a solvent. It was further diluted in DMSO to the desired concentrations for experimental use.

Cell lines and media. Human promyelocytic leukemia HL-60 cells were obtained from Korean Collection for Type Cultures (KCTC). SNU-1 (gastric carcinoma), A549 (lung carcinoma), HepG2 (hepatocellular carcinoma), and K562 (chronic myelogenous leukemia) cells were obtained from the American Type Culture Collection (ATCC). IMDM, RPMI and MEM media were purchased from GIBCO-BRL (Grand Island, NY). AcAsp-Glu-Val-Asp 7-amino-4-trifluoromethyl coumarin (AcDEVD-AFC) was obtained from Enzyme Systems Products (U.S.A.). Annexin V-FITC was purchased from BD Biosciences (U.S.A.). Camptothecin, propidium iodide (PI), MTT and DMSO were obtained from Sigma Chemical Co. (U.S.A.).

Cell cultures and cytotoxicity assay. HL-60 cells were cultured in IMDM supplemented with $20 \%$ fetal bovine serum and $100 \mathrm{IU} / 100 \mu \mathrm{g} / \mathrm{mL}$ penicillin/streptomycin at $37^{\circ} \mathrm{C}$ in $5 \%$ $\mathrm{CO}_{2}$ humidified incubator. A549, SNU-1, K562, and HepG2 cells were cultured in RPMI1640 and MEM with $10 \%$ FBS in a $\mathrm{CO}_{2}$ incubator at $37{ }^{\circ} \mathrm{C}$. The cytotoxicity of AC-264 was determined by the mitochondria-dependent reduction of 3-(4,5dimethylthiazol-2-yl)-2,5-diphenyltetrazolium bromide (MTT) to formazan. ${ }^{22}$ Briefly, exponentially growing cells were plated into 96-well plates, followed by treatment with different concentrations of AC-264 for $24 \mathrm{~h}$. Thereafter, MTT was added for another $4 \mathrm{~h}$-incubation at $37{ }^{\circ} \mathrm{C}$. Plates were analyzed on a Benchmark microplate reader (Bio-Rad, Hercules, CA, USA) at $570 \mathrm{~nm}$. All experiments were repeated at least twice with similar results. Cell viability in control medium with DMSO without any treatment was represented as $100 \%$.

Flow cytometric analysis. Extent of apoptosis was measured using Annexin V-FITC apoptosis detection kit (BD pharmingen, San Diego, CA) according to manufacturer's instruction. Briefly, $2 \times 10^{5}$ HL-60 cells in exponential growth were treated with AC-264 at $0,5,10,20$, and $40 \mu \mathrm{M}$ for 24 hours, and then washed 2 times with PBS. The cell pellet was gently re-suspended with Annexin binding buffer (10 mM HEPES/NaOH, $140 \mathrm{mM} \mathrm{NaCl}$, $2.5 \mathrm{mM} \mathrm{CaCl}_{2} ; \mathrm{pH} 7.4$ ) and stained with $5 \mu \mathrm{L}$ of Annexin VFITC and $5 \mu \mathrm{L}$ of propidium iodide (PI) at room temperature for $15 \mathrm{~min}$ in the dark. The reaction mixture was measured by FACS calibur (Becton Dickinson, NJ, USA) and stained cells analyzed by CellQuest.

Caspase-3 activity assay. After incubation with AC-264 at $0,5,10,20$, and $40 \mu \mathrm{M}$ for 24 hours, cells were harvested and washed once with cold PBS. The cells were lysed using $15 \mu \mathrm{L}$ of lysis buffer containing $10 \mathrm{mM}$ EDTA, $0.5 \%$ Triton X-100, and $10 \mathrm{mM}$ Tris- $\mathrm{HCl}(\mathrm{pH} 8.0)$ at room temperature for $10 \mathrm{~min}$. Lysates were transferred to fluorescent plate. For enzyme reaction, $100 \mu \mathrm{L}$ of assay buffer (100 mM HEPES; pH 7.5, $10 \mathrm{mM}$ dithiothreitol, $10 \%$ sucrose, $0.1 \%$ CHAPS, $0.1 \%$ BSA) and 10 $\mu \mathrm{L}$ of substrate (Ac-DEVD-AFC) were added in each well. Fluoroscene at $400 \mathrm{~nm}$ (excitation) and $505 \mathrm{~nm}$ (emission) was measured using LS50B fluorometer (PerkinElmer, Beaconsfield, UK) after incubation at $37^{\circ} \mathrm{C}$ for $1 \mathrm{~h}$.

TUNEL assay. Individual apoptotic cell death was observed using In Situ Cell Detection kit, AP (Roche, Mannheim, Ger- many) as described by the supplier's instruction. Briefly, HL-60 cells treated with 20 or $40 \mu \mathrm{M}$ of AC-264 for $24 \mathrm{~h}$ were harvested and washed with cold PBS. Cells were fixed with $4 \%(\mathrm{v} / \mathrm{v})$ formaldehyde at room temperature for $1 \mathrm{~h}$ on side-glass, washed with PBS and incubated in fresh permeabilization solution $(0.1 \%$ Triton $\mathrm{X}-100,0.1 \%$ sodium citrate) for $2 \mathrm{~min}$ on ice. After another wash, the cells were incubated with terminal deoxynucleotidyl transferase-mediated nick end labeling (TUNEL) reaction mixture and left on the slide for $1 \mathrm{~h}$ at $37^{\circ} \mathrm{C}$. Apoptotic cells were identified under fluorescence microscopy.

DNA fragmentation assay. After incubation with AC-264, cells were harvested and washed with PBS. Then apoptotic DNA was purified using Apoptotic DNA ladder kit (Roche, Mannheim, Germany). Briefly, cell pellets were lysed in $200 \mu \mathrm{L}$ of lysis buffer containing $10 \mathrm{mM}$ Tris- $\mathrm{HCl}$ (pH 8.0), $10 \mathrm{mM}$ Urea, $6 \mathrm{M}$ guanidine- $\mathrm{HCl}$ and $20 \%$ Triton $\mathrm{X}-100$ at room temperature for $10 \mathrm{~min}$. The lysate flowed to the filter and washed the filter with $4 \mathrm{mM} \mathrm{NaCl}, 0.4 \mathrm{mM}$ Tris- $\mathrm{HCl}(\mathrm{pH} 7.5)$ and $80 \%$ EtOH. The DNA bound to the filter was eluted with $200 \mu \mathrm{L}$ of elution buffer (10 mM Tris-HCl, $\mathrm{pH} 8.5)$. After isolated DNA was treated with RNase A $(100 \mu \mathrm{g} / \mathrm{mL})$ for $10 \mathrm{~min}$ at $37{ }^{\circ} \mathrm{C}$, DNA fragments were separated by $1.5 \%$ agarose gel containing $0.5 \mu \mathrm{g} / \mathrm{mL}$ of ethidium bromide and analyzed under UV illuminator.

Statistical analysis. Each experimental value was expressed as means \pm standard errors of the mean (SEMs). Statistical analysis was performed using Student's two-tailed t-test to compare independent means, employing Microsoft Excel.

\section{Results and Discussion}

Identification of a novel indole derivative AC-264 and its cytotoxicity against various cancer cells. The cell growth inhibitory and cytotoxic effects of the compounds were investigated by MTT assay with campothecin (CPT), a known anticancer agent, as a positive control. ${ }^{22-23}$

A total 50 compounds from our synthetic chemical library were screened for their potential cytotoxic effect on human promyelocytic leukemia HL-60 cells. The chemical library was constructed via derivatization of commercially available trans3 -indoleacrylic acid. Primary screening of the chemical library at $10 \mu \mathrm{M}$, followed by second screening of some selected compounds at the concentrations of 5,10 , and $20 \mu \mathrm{M}$, resulted in discovery of 3-(3-1H-Indol-3-yl-acryloylamino)- $N$-(2-piperidin-1-yl-ethyl)-benzamide (AC-264) as a novel lead (supporting information).

Since a variety of indole-based compounds have been reported to have potent anticancer effects, ${ }^{19-21}$ it was of great interest to investigate the effects of an indole-containing compound AC264 in regulating cell viability, particularly for tumor cells. The study was further designed to determine the dose-dependent effect of AC-264 on growth inhibition in several cancer cell lines, including K562, SNU-1, SK-OV-3, HepG2, A549 and HL-60 cells (Fig. 2). These results demonstrate that AC-264 showed different degrees of cytotoxicity on these cells based on the $\mathrm{IC}_{50}$ values (Table 1), in particular, AC-264 inhibited the growth of HL-60 cells in a dose-dependent manner as shown in Fig. 2. Of interest, the leukemia HL-60 cell line is known to 


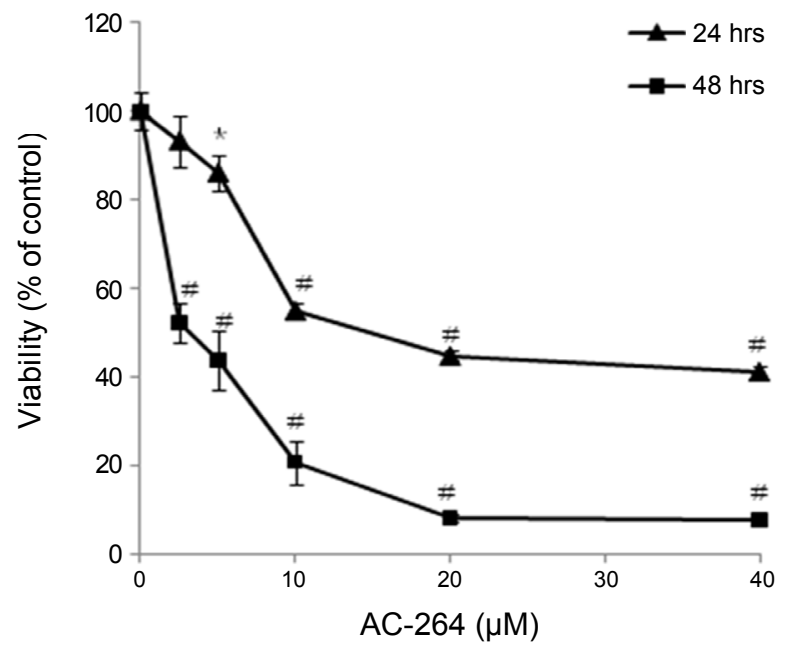

Figure 2. Cytotoxic effects of AC-264 in HL-60 cells. Cells were incubated with different concentrations of AC-264 for $24 \mathrm{~h}$ or $48 \mathrm{~h}$. Cytotoxicity was measured by MTT assay. Results are expressed as means \pm SEMs. *; $<<0.05, \# ; \mathrm{p}<0.005$ (Student's t-test) compared with naive cells.

be a useful model to study apoptosis of leukemia cells. ${ }^{24-25}$

Flow cytometric estimation of AC-264 induced apoptosis and necrosis. In the early stages of apoptosis, phosphatidylserine (PS) is translocated to the outer layer of the membrane i.e. the external surface of the cell and cell membrane remains intact. On the other hand, it features loss of membrane integrity and leakage of cellular constituents into the environment in necrosis. Annexin V binds preferentially to PS, which is normally
Table 1. Cytotoxic activity of AC-264 on cancer cell lines

\begin{tabular}{ccc}
\hline \multirow{2}{*}{ Cell line } & \multicolumn{2}{c}{$\mathrm{AC}-264 ; \mathrm{IC}_{50}(\mu \mathrm{M})^{a}$} \\
\cline { 2 - 3 } & $24 \mathrm{hrs}$ & $48 \mathrm{hrs}$ \\
\hline K562 & $37.63 \pm 0.18$ & $31.89 \pm 0.16$ \\
SNU-1 & $21.54 \pm 0.12$ & $25.71 \pm 0.10$ \\
SK-OV-3 & $50.99 \pm 5.83$ & $33.25 \pm 0.12$ \\
HepG2 & $30.45 \pm 0.19$ & $21.01 \pm 0.15$ \\
A549 & $21.15 \pm 0.24$ & $16.14 \pm 0.26$ \\
HL60 & $19.82 \pm 0.10$ & $14.55 \pm 0.17$ \\
\hline
\end{tabular}

${ }^{a} \mathrm{IC}_{50}$ is defined as the concentration that results in a $50 \%$ decrease in the number of cells compared to that of the control cultures in the absence of any compound. The values represent the means of results from three independent experiments with similar patterns. $\mathrm{IC}_{50}$ of CPT is $0.80 \pm 0.13 \mu \mathrm{M}$.

absent in the outer leaflet of the plasma membrane. This means that Annexin V discriminate between apoptotic and non-apoptotic cells. ${ }^{26}$ Accordingly, Annexin V binding assay combined with propidium iodide (PI) was used to collect information about the integrity of the cell membrane. ${ }^{27}$

After HL-60 cells were incubated with different concentration of AC-264, cells were stained with Annexin V-FITC and PI which can assess the early apoptotic and late apoptotic cell population (Fig. 3). AC-264 produced a dose-dependent increase in the apoptotic cell population. The basal apoptotic population in the untreated cell was $4.27 \%$, which increased to $36.45 \%$ at $40 \mu \mathrm{M}$. This result suggests that AC-264 induced apoptosis in the primary mode of cell death.

Effect of AC-264 on the cell morphology. The growth-inhibitory effect of AC-264 was accompanied by cell shrinkage as
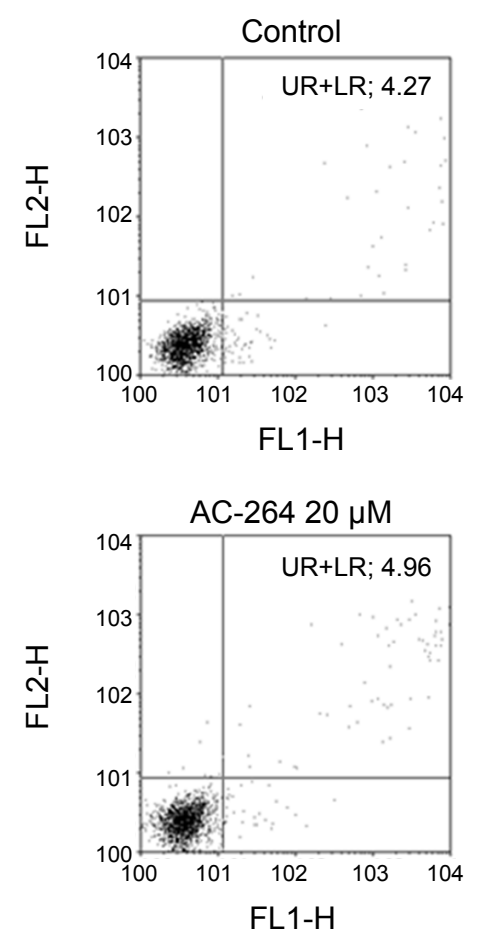
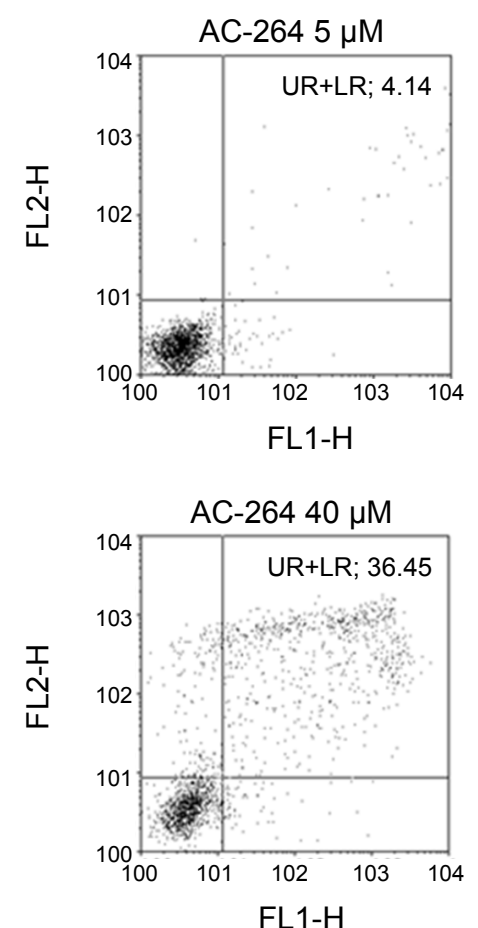
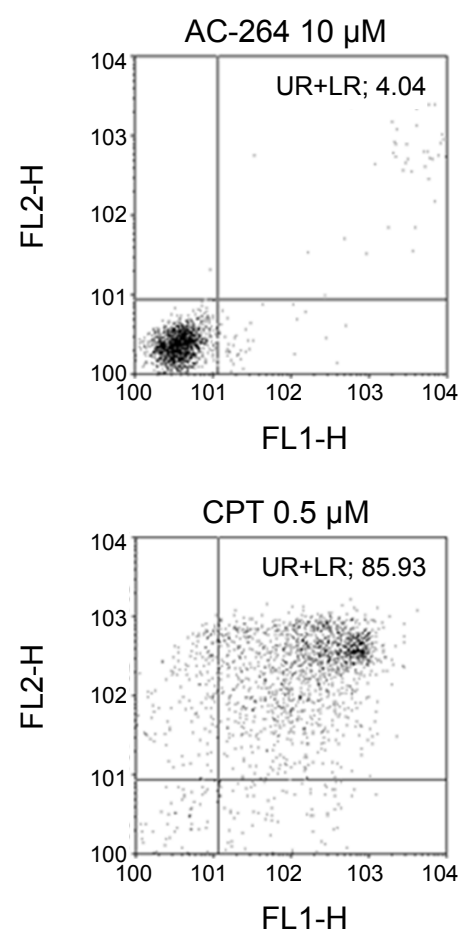

Figure 3. Flow cytometric analysis of AC-264-induced apoptosis in HL-60 cells. Cells were incubated with indicated concentrations of $0,5,10,20$, and $40 \mu \mathrm{M}$ AC-264 for $24 \mathrm{~h}$. Apoptosis was analyzed by Annexin V-FITC/PI staining method. Cells in the lower right quadrant represented early apoptosis and in the upper right quadrant represented late apoptosis. Data are representative of one of three similar experiments. 
(a) $\mathrm{AC}-2640 \mu \mathrm{M}$

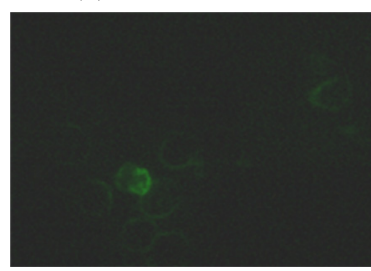

(c) AC-264 $40 \mu \mathrm{M}$

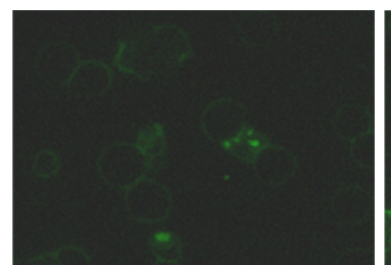

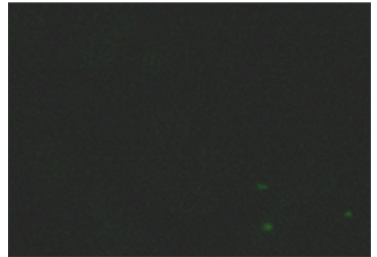

(d) AC-264 $0.5 \mu \mathrm{M}$

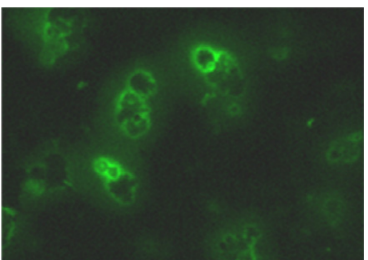

Figure 4. TUNEL assay of AC-264-induced apoptosis in HL-60 cells. Cells were incubated with concentrations of 0,20 , and $40 \mu \mathrm{M}$ of AC264 for $24 \mathrm{~h}$. Apoptotic cells were visualized by LEICA fluorescence microscope. Condensed and fragmented nuclei and apoptotic bodies were found in the AC-264-treated cells, but not in the control.

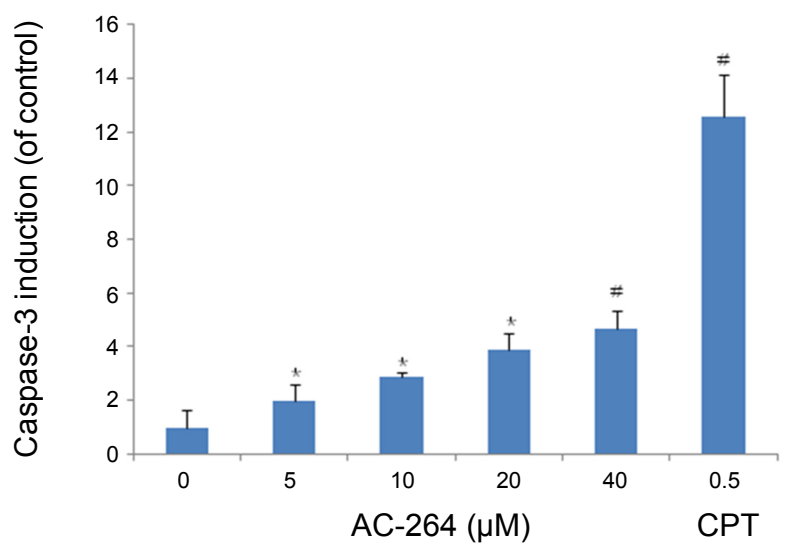

Figure 5. Caspase-3 activity of AC-264-induced apoptosis in HL-60 cells. Cells were incubated with different concentrations of AC-264 for $24 \mathrm{~h}$. Cell lysates were reacted with substrate (Ac-DEVD-AFC) for $1 \mathrm{~h}$. Fluoroscene at $400 \mathrm{~nm}$ (excitation) and $505 \mathrm{~nm}$ (emission) was measured using LS50B fluorometer. Results are expressed as means \pm SEMs. *; $<<0.05, \# ; p<0.005$ (Student's t-test) compared with naive cells.

observed by microscope, which may indicate apoptotic cell death. We examined the morphological changes of AC-264treated cells by TUNEL kit. This method is based on the transfer of labeled dNTP to 3'-OH ends of DNA fragments by terminal deoxynucleotidyl transferase. The control cells were normal and the nuclei were round and homogeneous (Fig. 4a), while the cells treated with AC-264 exhibited the characteristics of apoptosis, with cell shrinkage, nuclear condensation and fragmentation (Fig. 4c).

Effect of AC-264 on activation of Caspase-3 and DNA fragmentation in HL-60 cells. Apoptosis induced by anticancer agents has been associated with alteration in two general pathways. One pathway is the extrinsic pathway initiated by the binding of an extracellular death ligand, such as FasL to Fas. ${ }^{28}$ The other pathway is the intrinsic pathway is mediated by mitochondrial alterations. ${ }^{29}$

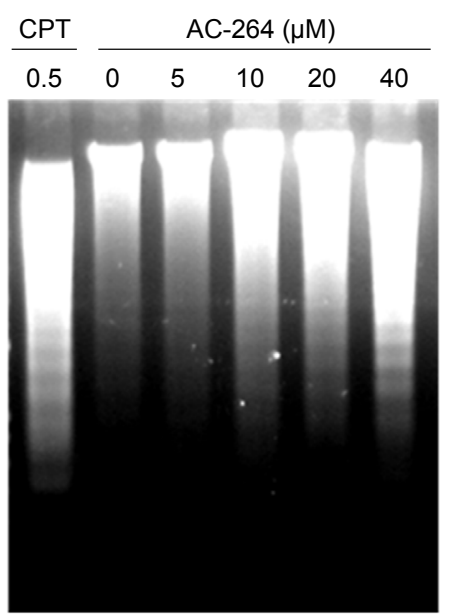

Figure 6. DNA fragmentation of AC-264-induced apoptosis in HL-60 cells. Cells were incubated with different concentrations of AC-264 for $24 \mathrm{~h}$. DNA ladders reflecting the presence of DNA fragments were viewed on ethidium bromide-stained agarose gel.

One of the most consistently appeared features of apoptosis is the activation of cytosolic cysteine proteases, such as caspases leading to the loss of cellular structure and function, and ultimately resulting in cell death. ${ }^{30}$ In particular, caspase- $3,-8$, and -9 play crucial roles in the process of apoptosis. ${ }^{31}$ According to apoptotic stimuli, caspase- 8 is activated through a death receptor mediated pathway and cleavage of caspase- 9 plays a key role in mitochondria apoptotic pathway. ${ }^{32}$ To examine the effect of AC-264 on caspase- 3 activation, HL-60 cells were treated with AC-264 for $24 \mathrm{~h}$. The caspase-3-specific fluorogenic substrate (DEVD-AFC) was used for fluorometric assay. As shown in Fig. 5, it was found that AC-264 induced activation of caspase- 3 in a dose-dependent manner. The induction of DNA fragmentation was demonstrated by incubating HL-60 cells with AC-264 at different concentrations (5, 10, 20 and 40 $\mu \mathrm{M})$. To examine the effect of AC-264 on caspase- 3 , the DNA of HL-60 cells was treated with different concentrations of AC264, which resulted in DNA fragmentation in similar patterns of that with CPT (Fig. 6). A ladder pattern of DNA internucleosomal fragmentation was observed after treating cells with AC264 at $10 \mu \mathrm{M}$. These results, taken together with the findings on caspase- 3 activation, suggest that treatment with AC-264 caused the cells to become apoptotic.

\section{Conclusions}

In summary, these results suggest that AC-264 inhibited the growth of human myeloid cell line HL-60 cells via caspase-3 activation and internucleosomal DNA fragmentation. An indole-containing compound AC-264 may be useful as a novel lead for development of cancer suppressor and/or chemotherapeutic agent against cancer. In vivo antitumor efficacy evaluation and pharmacokinetic study is in progress and the results will be reported elsewhere.

Acknowledgments. This work was supported by the Dongguk University Research Fund of 2010, Korea. 


\section{References}

1. Steller, H. Science 1995, 267, 1445.

2. Chris Bleackley, R.; Heibein, J. A. Nat. Prod. Rep. 2001, 18, 431.

3. Lawen, A. BioEssays 2003, 25, 888.

4. Danial, N. N.; Korsmeyer, S. J. Cell 2004, 116, 205.

5. Shi, Y. G. Structure 2002, 10, 285.

6. Zimmermann, K. C.; Bonzon, C.; Green, D. R. Pharmacol. Ther. 2001, 92, 57.

7. Wang, X. D. Gene Dev. 2001, 15, 2922.

8. Enari, M.; Sakahira, H.; Yokoyama, H.; Okawa, K.; Iwamatsu, A.; Nagata, S. Nature 1998, 391, 43.

9. Ha, K. S.; Kim, K. M.; Kwon, Y. G.; Bai, S. K.; Nam, W. D.; Yoo, Y. M. FASEB J. 2003, 17, 1036

10. Tibbetts, M. D.; Zheng, L.; Lenardo, M. J. Nat. Immunol. 2003, 4, 404.

11. Stefanis, L.; Troy, C. M.; Qi, H.; Greene, L. A. J. Neurochem. 1997, 69, 1425

12. Wu, L. W.; Reid, S.; Ritchie, A.; Broxmeyer, H. E.; Donner, D. B. Blood Cells Mol. Dis. 1999, 25, 20.

13. Gray, J.; Haran, M. M.; Schneider, K.; Vesce, S.; Ray, A. M.; Owen, D. J. Biol. Chem. 2001, 276, 32750.

14. King, K. L.; Cidlowski, J. A. Annu. Rev. Physiol. 1998, 60, 601.

15. Djavaheri-Mergny, M.; Wietzerbin, J.; Besancon, F. Oncogene 2003, 22, 2558.

16. Hostanska, K.; Vuong, V.; Rocha, S.; Soengas, M. S.; Glanzmann, C.; Saller, R. Br. J. Cancer 2003, 88, 1785.

17. Utz, P. J.; Anderson, P. Cell Death Differ. 2000, 7, 589.

18. Vial, J. P.; Belloc, F.; Dumain, P.; Besnard, S.; Lacombe, F.; Boi- sseau, M. R.; Reiffers, J.; Bernard, P. Leukemia Res. 1997, 21, 163.

19. Kuo, C. C.; Hsieh, H. P.; Pan, W. Y.; Chen, C. P.; Liou, J. P.; Lee, S. J.; Chang, Y. L.; Chen, L. T.; Chen, C. T.; Chang, J. Y. Cancer Res. 2004, 64, 4621.

20. Kim, S. Y.; Kim, M. K.; Kwon, S. B.; Na, J. I.; Park, K.C.; Kim, D. S. Arch. Dermatol. Res. 2009, 301, 319.

21. Hashimoto, T.; Ashida, H.; Sano, T.; Furuyashiki, T.; Shiotani, B.; Kanazawa, K.; Danno, G. Mutat. Res. 2000, 457, 57.

22. King, M. A.; Radicchi-Mastroianni, M. A. Cytometry 2002, 49, 28.

23. Baisch, H.; Bollmann, H.; Bornkessel, S. Cell Prolif. 1999, 32, 303.

24. Jeong, G. S.; Kwon, O. K.; Park, B.Y.; Oh, S. R.; Ahn, K. S.; Chang, M. J.; Oh, W. K.; Kim, J. C.; Min, B. S.; Kim, Y. C.; Lee, H. K. Biol. Pharm. Bull. 2007, 30, 1340.

25. Li, M.; Min, J. M.; Cui, J. R.; Zhang, L. H.; Wang, L.; Valette, A.; Davrinche, C.; Wright, M.; Leung-Tack, J. Nutrition and Cancer 2002, 42, 241.

26. Vermes, I.; Haanen, C.; Steffens-Nakken, H.; Reutelingsperger, C. J. Immunol. Methods 1995, 184, 39.

27. King, M. A.; Radicchi-Mastroianni, M. A.; Wells, J. V. Cytometry 2000, 40,10

28. Ashkenazi, A.; Dixit, V. M. Science 1998, 281, 1305.

29. Green, D. R.; Reed, J. C. Science 1998, 281, 1309.

30. Stennickes, H. T.; Salvesen, G. S. J. Biol. Chem. 1997, 272, 25719.

31. Shi, Y. Mol. Cell 2002, 9, 459.

32. Nunez, G.; Benedict, M. A.; Hu, Y.; Inohara, N. Oncogene 1998, $17,3237$. 